\title{
Hubungan Tingkat Pengetahuan dan Personal Hygiene terhadap Kejadian Pedikulosis Kapitis pada Anak Asuh di Panti Asuhan Liga Dakwah Sumatera Barat
}

\author{
Annisa Anggraini ${ }^{1}$, Qaira Anum ${ }^{2}$, Machdawaty Masri $^{3}$
}

\begin{abstract}
Abstrak
Pedikulosis kapitis adalah infeksi kulit dan rambut kepala yang disebabkan infestasi Pediculus humanus var. capitis. Kejadian pedikulosis kapitis cukup tinggi di daerah lingkungan padat seperti panti asuhan. Prevalensi pedikulosis kapitis yang tinggi di panti asuhan menyebabkan anak asuh mengalami gangguan psikis dan fisik. Tujuan penelitian ini adalah menentukan hubungan tingkat pengetahuan mengenai pedikulosis kapitis dan personal hygiene terhadap pedikulosis kapitis. Metode penelitian berupa survei analitik cross sectional yang dilaksanakan pada dari Januari sampai November 2016 di Panti Asuhan Liga Dakwah Sumatera Barat. Pengumpulan data menggunakan kuisioner terhadap 69 orang anak asuh yang bersedia menjadi responden. Hasil penelitian menunjukan lebih dari setengah responden (58\%) memiliki pedikulosis kapitis positif, responden lebih dominan memiliki tingkat pengetahuan yang tinggi $(88,4 \%)$ dan responden lebih banyak memiliki personal hygiene yang baik $(81,2 \%)$. Analisis data untuk mengetahui hubungan tingkat pengetahuan dan personal hygiene terhadap pedikulosis kapitis yaitu menggunakan uji Chi-square yang menunjukkan bahwa tidak ada hubungan antara tingkat pengetahuan mengenai pedikulosis kapitis terhadap kejadian pedikulosis kapitis dengan nilai $p=0,126$ dan tidak ada hubungan antara personal hygiene terhadap kejadian pedikulosis kapitis dengan nilai $p=0,548$.
\end{abstract}

Kata kunci: tingkat pengetahuan, personal hygiene, pedikulosis kapitis

\section{Abstract}

Pediculosis capitis is an infection of the skin and hair of the head caused infestation Pediculus humanus var. capitis. Pediculosis capitis is quite high in the dense environments such as orphanages. The prevalence of pediculosis capitis high in orphanages causing children suffered physical and psychological disorders. The objective of this study was to determine the correlation of the level of knowledge and personal hygiene with incidence pediculosis capitis. This research used cross sectional analytical survey on January until November 2016 in Liga Dakwah West Sumatra Orphanage. Collecting data using questionnaires in 69 children who are willing to become respondents. The results showed more than half of respondents (58\%) had a positive pediculosis capitis, more dominant respondents have a high level of knowledge (88.4\%) and respondents were more likely to have good personal hygiene (81.2\%).Analysis of data to determine the correlation of the level of knowledge and personal hygiene with incidence pediculosis capitis was using Chi-square test which showed there was no correlation between the level of knowledge about pediculosis capitis on the incidence of pediculosis capitis $p=0.126$ and there is no correlation between personal hygiene on the incidence of pediculosis capitis $p=0.548$.

Keywords: level of knowledge, personal hygiene, pediculosis capitis

Affiliasi penulis: 1. Prodi Pendidikan Dokter Fakultas Kedokteran Universitas Andalas Padang (FK Unand) 2. Bagian IImu Kesehatan Kulit dan Kelamin FK Unand, 3. Bagian Kimia FK Unand
Korespondensi: Annisa Anggraini,

Email: annisaanggraini13.aa@gmail.com Telp: 082386278364 


\section{PENDAHULUAN}

Pedikulosis kapitis adalah salah satu klasifikasi dari pedikulosis yaitu infeksi kulit kepala atau rambut pada manusia yang disebabkan oleh Pediculus. ${ }^{1}$ Parasit yang menyebabkan pedikulosis kapitis adalah Pediculus humanus var.capitis. ${ }^{2}$ Pediculus humanus var. capitis merupakan ektoparasit pada manusia yang permanen dan tersebar di seluruh dunia. ${ }^{3}$

Laporan angka kejadian pedikulosis kapitis telah ada sejak tahun 1970-an, semenjak itu kasusnya terus mengalami peningkatan diberbagai negara. ${ }^{4}$ Angka kejadian penyakit pedikulosis kapitis dimulai dari ratusan hingga jutaan kasus di seluruh dunia. ${ }^{5}$ Kejadian pedikulosis kapitis di United States diperkirakan telah tercatat dari 6 sampai 12 juta per tahun. ${ }^{5}$ Prevalensi kejadian pedikulosis kapitis sebesar $13,1 \%$ di negara Turki. $^{6}$ Kejadian di Indonesia berdasarkan penelitian yang dilakukan sekitar Kota Yogyakarta didapatkan anak-anak yang menderita pedikulosis kapitis yaitu 19,6\%. ${ }^{7}$

Pedikulosis kapitis memberikan gejala paling dominan berupa rasa gatal terutama pada daerah oksiput dan temporal serta dapat meluas keseluruh bagian kepala. ${ }^{1}$ Kelainan kulit yang timbul disebabkan oleh garukan untuk menghilangkan rasa gatal yang terjadi akibat pengaruh liur dan ekskreta kutu didalam kulit waktu menghisap darah. ${ }^{8}$ Pedikulosis kapitis juga sering menyebabkan masalah sosial seperti berkurangnya rasa percaya diri, stigma sosial yang negatif, kurangnya kualitas tidur, serta sering mengalami gangguan belajar. ${ }^{9}$

Penyakit yang dapat merusak kualitas hidup ini biasanya dialami anak-anak berumur 3-12 tahun. ${ }^{10}$ Pada usia $>15$ tahun seseorang masih bisa terjangkit pedikulosis kapitis meskipun tidak termasuk lagi ke dalam usia yang rentan (<15 tahun). ${ }^{11}$ Prevalensi anak perempuan yang mengalami pedikulosis kapitis ditemukan lebih banyak dari pada anak laki-laki. ${ }^{12}$

Pedikulosis kapitis yang disebabkan Pediculus humanus var. capitis ini merupakan infestasi parasit yang tinggi penularanya. ${ }^{1}$ Pengetahuan terhadap pedikulosis kapitis sangat penting karena dapat mencegah adanya transmisi atau penularan kepada orang lain, kontak dari kepala ke kepala merupakan penularan atau transmisi terbanyak. ${ }^{5}$

Pedikulosis kapitis dapat ditemukan ditempat pengungsian, tuna wisma, dan perkampungan kumuh. ${ }^{3}$ Pedikulosis kapitis sering juga terjadi dan cepat meluas dalam lingkungan hidup yang padat, misalnya di asrama dan di panti asuhan. ${ }^{1}$ Hal ini sangat berhubungan dengan kondisi kehidupan sosial ekonomi seseorang seperti keadaan kurang mampu. ${ }^{4}$

Penelitian dilakukan di Panti Asuhan Liga Dakwah Sumatera Barat, kriteria penelitian sesuai dengan informasi awal yang didapatkan bahwa anak asuh di Panti Asuhan Liga Dakwah Sumatera Barat semuanya berjenis kelamin perempuan, anak asuh ada yang mengalami pedikulosis kapitis dan belum pernah dilakukan penelitian mengenai hal ini sebelumnya. Jumlah anak asuh di panti asuhan tersebut juga memenuhi besar sampel yang dibutuhkan dalam penelitian ini, oleh karena itu peneliti tertarik melakukan penelitian tentang hubungan tingkat pengetahuan mengenai pedikulosis kapitis dan personal hygiene terhadap kejadian pedikulosis kapitis pada anak-asuh di Panti Asuhan Liga Dakwah Sumatera Barat pada tahun 2016

\section{METODE}

Jenis penelitian ini adalah survei analitik cross sectional yang dilakukan dari Januari sampai November 2016. Populasi penelitian yaitu semua anak asuh di Panti Asuhan Liga Dakwah Sumatera Barat pada tahun 2016 yang berjumlah 75 orang dengan jenis kelamin perempuan dan usia 11-20 tahun dengan besar sampel sebanyak 69 orang.

Variabel independen adalah tingkat pengetahuan dan personal hygiene, variabel dependen adalah pedikulosis kapitis. Pengambilan data dilakukan dengan cara responden mengisi kuisioner yang sudah dilakukan uji validitas dan reliabilitas yang terdiri dari 30 buah pernyataan untuk tingkat pengetahuan dan 20 buah pertanyaan untuk personal hygiene. Langkah pengolahan data meliputi editing, coding, data entry dan cleaning. Analisis data menggunakan uji chi-square. 
HASIL

\section{Analisis Univariat}

Tabel 1. Karakteristik responden pada anak asuh di Panti Asuhan Liga Dakwah Sumatera Barat

\begin{tabular}{lcc}
\hline \multicolumn{1}{c}{ Karakteristik } & Frekuensi & $\%$ \\
\hline Usia & 9 & 13,1 \\
11 - 12 tahun & 23 & 33,3 \\
13 - 14 tahun & 27 & 39,1 \\
$15-16$ tahun & 7 & 10,1 \\
17 - 18 tahun & 3 & 4,4 \\
19 - 20 tahun & & \\
Tingkat Sekolah & 35 & 50,7 \\
SMP & 34 & 49,3 \\
SMA & & \\
\hline
\end{tabular}

Berdasarkan Tabel 1 dapat disimpulkan responden terbanyak adalah anak asuh yang berusia 15 - 16 tahun yaitu sebanyak 27 orang (39,1\%) serta tingkat sekolah yang terbanyak adalah SMP yaitu 35 orang $(50,7 \%)$.

Tabel 2. Distribusi frekuensi kejadian pedikulosis kapitis pada anak asuh di Panti Asuhan Liga Dakwah Sumatera Barat.

\begin{tabular}{lcc}
\hline $\begin{array}{l}\text { Pedikulosis } \\
\text { Kapitis }\end{array}$ & Frekuensi & $\%$ \\
\hline Positif & & \\
Negatif & 40 & 58 \\
\hline Jumlah & 29 & 42 \\
\hline
\end{tabular}

Berdasarkan Tabel 2 didapatkan bahwa lebih banyak anak asuh yang menderita pedikulosis kapitis dari pada yang tidak menderita pedikulosis kapitis dengan angka kejadian pedikulosis kapitis yaitu sebesar 40 orang $(58,0 \%)$.

Tabel 3. Distribusi frekuensi tingkat pengetahuan mengenai pedikulosis kapitis pada anak asuh di Panti Asuhan Liga Dakwah Sumatera Barat.

\begin{tabular}{lcc}
\hline Tingkat & Frekuensi & $\%$ \\
Pengetahuan & & \\
\hline Tinggi & 61 & 88,4 \\
Rendah & 8 & 11,6 \\
\hline Jumlah & 69 & 100
\end{tabular}

Berdasarkan Tabel 3 didapatkan sebagian besar (88,4 \%) anak asuh Panti Asuhan liga Dakwah Sumatera Barat memiliki tingkat pengetahuan yang tinggi mengenai penyakit pedikulosis kapitis.

Tabel 4. Distribusi frekuensi personal hygiene pada anak asuh di Panti Asuhan Liga Dakwah Sumatera Barat.

\begin{tabular}{lcc}
\hline Personal Hygiene & Frekuensi & $\%$ \\
\hline Baik & 56 & 81,2 \\
Buruk & 13 & 18,8 \\
\hline Jumlah & 69 & 100 \\
\hline
\end{tabular}

Berdasarkan Tabel 4 didapatkan sebagian besar (81,2 \%) anak asuh di Panti Asuhan Liga Dakwah Sumatera Barat memiliki personal hygiene yang baik.

\section{Analisi Bivariat}

Tabel 5. Hubungan tingkat pengetahuan pedikulosis kapitis dengan kejadian pedikulosis kapitis pada anak asuh di Panti Asuhan Liga Dakwah Sumatera Barat.

\begin{tabular}{|c|c|c|c|c|c|c|}
\hline \multirow{4}{*}{$\begin{array}{c}\text { Tingkat } \\
\text { Pengetahuan }\end{array}$} & \multicolumn{4}{|c|}{ Pedikulosis Kapitis } & & \multirow{4}{*}{$\mathbf{p}$} \\
\hline & \multirow{2}{*}{\multicolumn{2}{|c|}{ Positif }} & \multirow{2}{*}{\multicolumn{3}{|c|}{$\begin{array}{l}\text { Negatif } \\
\text { Jumlah }\end{array}$}} & \\
\hline & & & & & & \\
\hline & $f$ & $\%$ & $f$ & $\%$ & $f$ & \\
\hline Tinggi & 33 & 54,1 & 28 & 45,9 & 61 & \\
\hline Rendah & 7 & 87,5 & 1 & 12,5 & 8 & 0,126 \\
\hline Total & 40 & 58,0 & 29 & 42,0 & 69 & \\
\hline
\end{tabular}

Pada Tabel 5 dapat diketahui bahwa tidak terlihat adanya hubungan yang signifikan antara tingkat pengetahuan mengenai pedikulosis kapitis dengan kejadian pedikulosis kapitis pada anak asuh di Panti Asuhan Liga Dakwah Sumatera Barat $(p=$ 0,126).

Berdasarkan Tabel 6 dapat diketahui bahwa tidak terlihat adanya hubungan yang signifikan antara personal hygiene dengan kejadian pedikulosis kapitis pada anak asuh di Panti Asuhan Liga Dakwah Sumatera Barat $(p=0,548)$ 
Tabel 6. Hubungan personal hygiene dengan kejadian pedikulosis kapitis pada anak asuh di Panti Asuhan Liga Dakwah Sumatera Barat.

\begin{tabular}{|c|c|c|c|c|c|c|}
\hline \multirow{4}{*}{$\begin{array}{l}\text { Personal } \\
\text { Hygiene }\end{array}$} & \multicolumn{6}{|c|}{ Pedikulosis Kapitis } \\
\hline & \multirow{2}{*}{\multicolumn{2}{|c|}{ Positif }} & \multicolumn{4}{|c|}{ Negatif } \\
\hline & & & \multicolumn{3}{|c|}{ Jumlah } & \multirow{2}{*}{ p } \\
\hline & f & $\%$ & $f$ & $\%$ & $f$ & \\
\hline Baik & 31 & 55,4 & 25 & 44,6 & 56 & \multirow[b]{2}{*}{0,548} \\
\hline Buruk & 9 & 69,2 & 4 & 30,8 & 13 & \\
\hline Total & 40 & 58,0 & 29 & 42,0 & 69 & \\
\hline
\end{tabular}

\section{PEMBAHASAN}

\section{Analisis Univariat}

Anak asuh di Panti Asuhan Liga Dakwah Sumatera Barat berjumlah sebanyak 69 orang yang semuanya berjenis kelamin perempuan, dimana paling banyak berusia 15 - 16 tahun yaitu 27 orang $(39,1 \%)$ dan tingkat sekolah yang terbanyak adalah SMP yaitu 35 orang $(50,7 \%)$. Hasil frekuensi distribusi responden penelitian ini sesuai dengan penelitian di Panti Asuhan Kelurahan Sekip Jaya Kecamatan Kemuning Palembang bahwa responden yang terbanyak antara tingkat pendidikan SMP dan SMA pada panti asuhan tersebut adalah SMP yaitu $34,5 \%{ }^{13}$

Frekuensi distribusi usia pada penelitian ini memiliki kesamaan dengan penelitian lain bahwa usia responden yang terbanyak adalah $>15$ tahun yaitu 38 orang $(63,3 \%){ }^{14}$ Penelitian tersebut masih memiliki kesamaan bahwa usia 16 tahun termasuk dalam kategori responden yang terbanyak sesuai dengan penelitian ini. Kejadian pedikulosis kapitis hampir merata pada semua umur, adanya pedikulosis kapitis karena interaksi penderita pedikulosis kapitis dengan orang lain bias terjadi kepada siapa saja yang masih berada di dalam lingkungan tersebut. ${ }^{15}$

Pada penelitian ini ditemukan lebih dari setengah jumlah responden yang mengalami pedikulosis kapitis, terdapat 40 orang (58,0\%) mengalami pedikulosis kapitis dan sebanyak 29 orang $(42,0 \%)$ responden tidak mengalami pedikulosis kapitis. Tingginya angka kejadian pedikulosis kapitis ini dipengaruhi oleh faktor seperti faktor sosioekonomi, kepadatan lingkungan dan jenis rambut seseorang. ${ }^{10}$
Tingkat pengetahuan pedikulosis kapitis pada responden yang paling banyak adalah pengetahuan tinggi sebanyak 61 orang $(88,4 \%)$. Umur berhubungan erat dengan tingkat pengetahuan seseorang. ${ }^{16}$ Seseorang yang lebih tua memiliki pengetahuan yang lebih baik dan lebih luas. ${ }^{17}$ Hasil penelitian personal hygiene pada responden adalah personal hygiene baik lebih banyak yaitu 56 orang $(81,2 \%)$ dari pada personal hygiene yang buruk yaitu 13 orang (18,8 \%). Seseorang yang berusia lebih dewasa maka pengetahuanya juga akan lebih banyak dan cenderung untuk berperilaku lebih baik, hal tersebut sesuai dengan perilaku responden terhadap personal hygiene dalam penelitian ini, terlihat tingginya angka personal hygiene yang baik pada responden mungkin dipengaruhi oleh faktor umur karena umur dewasa akan mampu melaksanakan personal hygiene dengan baik, karena responden tinggal dilingkungan yang padat maka kebiasaan personal hygiene yang baik ini dapat disebarkan pada populasi di tempat itu. ${ }^{16}$

\section{Analisi Bivariat}

Uji statistik Chi-square untuk mengetahui hubungan antara tingkat pengetahuan pedikulosis kapitis dengan kejadian pedikulosis kapitis, berdasarkan hasil analisis didapatkan nilai $p=0,126$ $(p=>0,05)$ dimana nilai signifikasi untuk berhubungan seharusnya $p<0,05$ dan dari hasil tersebut menunjukan bahwa tidak terdapat hubungan yang bermakna antara tingkat pengetahuan mengenai pedikulosis kapitis dengan kejadian pedikulosis kapitis.

Tidak ada hubungan tingkat pengetahuan pedikulosis kapitis dengan kejadian pedikulosis kapitis disebabkan karena tingkat pengetahuan sangat erat kaitanya dengan sikap individu. Orang yang memiliki tingkat pengetahuan yang tinggi tetapi tidak dapat mengendalikan emosinya, tidak disertai kemauan dan tidak disikapi dengan tindakan untuk mengurangi penularanya untuk bersikap sesuai dengan tingkat pengetahuanya maka akan meningkatkan prevalensi suatu penyakit seperti pedikulosis kapitis. ${ }^{16}$ Tingginya tingkat pengetahuan pada penelitian ini disebabkan karena kecendrungan seseorang untuk mencari tahu, jika dalam suatu populasi telah ada individu yang mengalami situasi pedikulosis kapitis maka akan ada 
seseorang yang mencari tahu tentang pedikulosis kapitis sehingga tingkat pengetahuan orang tersebut bisa menyebarluaskan kepada yang lain. ${ }^{18}$

Analisis uji Chi-square untuk mengetahui hubungan antara personal hygiene dengan kejadian pedikulosis kapitis, berdasarkan hasil analisis didapatkan nilai $p=0,548$ dimana nilai signifikasi untuk berhubungan seharusnya $p<0,05$ dan hasil tersebut menunjukkan bahwa tidak terdapat hubungan yang bermakna antara personal hygiene dengan kejadian pedikulosis kapitis.

Tidak terdapat hubungan yang bermakna mungkin bisa karena kualitas mencuci rambut dapat memengaruhi infestasi pedikulosis kapitis, pada orang yang sering mencuci rambut setiap hari membuat kulit kepala menjadi bersih, hal itu memungkinkan kutu mendapatkan suplai makanan yang optimal, dan seringnya mencuci rambut pada penderita pedikulosis kapitis akan membuat kondisi kulit kepala menjadi lembab dan kondisi itu sangat menguntungkan bagi telur kutu untuk perkembanganya, sehingga orang yang rajin mencuci rambutnya setiap hari juga bisa mendapatkan pedikulosis kapitis. ${ }^{18}$

Faktor yang mempengaruhi pedikulosis sangat banyak sekali, walaupun personal hygiene seseorang baik tetapi masih tinggal serumah dengan penderita pedikulosis kapitis dalam lingkungan yang sangat padat dan tidak melakukan pengobatan pedikulosis kapitis secara bersamaan akan membuat penularan pedikulosis kapitis selalu terjadi. Selain faktor tingkat pengetahuan dan personal hygiene, tingginya kejadian pedikulosis kapitis juga dapat ditemukan akibat pengaruh dari musim, umur, status sosio ekonomi, panjang rambut, lokasi tempat tinggal berada di desa atau di kota, adanya edukasi dan kontrol sikap terhadap pedikulosis kapitis oleh orang tua kebiasaan interaksi dengan hewan peliharaan juga dapat menyebabkan pedikulosis kapitis. ${ }^{19}$

\section{SIMPULAN}

Tidak terdapat hubungan antara tingkat pengetahuan mengenai pedikulosis kapitis dengan kejadian pedikulosis kapitis pada anak asuh di Panti Asuhan Liga Dakwah Sumatera Barat.
Tidak terdapat hubungan antara personal hygiene dengan kejadian pedikulosis kapitis pada anak asuh di Panti Asuhan Liga Dakwah Sumatera Barat

\section{UCAPAN TERIMA KASIH}

Terima kasih kepada semua pihak atas bimbingan, bantuan, dan motivasi dalam penelitian ini serta semua pihak lainnya yang telah memberikan kontribusi dalam pelaksanaan penelitian ini.

\section{DAFTAR PUSTAKA}

1. Handoko RP. Pediculosis. Dalam: Djuanda A, Hamzah M, Aisah $S$, editor (penyunting). IImu penyakit kulit dan kelamin. Jakarta. Balai penerbit FKUI; 2005

2. Siregar. Saripati penyakit kulit. Jakarta: EGC;2005.

3. Buczek A, Markowska GD, Widomska, Iwona M. Pediculosis capitis among school children in urban and rural areas of poland. European Journal of Epidemiology. 2004:19:491-5.

4. Chosidow O. Scabies and pediculosis. The Lancet. 2000;355:819-26.

5. Bohl B, Evetts J, McClain K, Rosenauer A, Stellitano W. Clinical practice update: Pediculosis capitis. Continuing Nurse Education. 2015;41(5): 227-34

6. Gulgun M, Elcin B, Abdulbaki B, Oguzhan B, Turker T. Pediculosis capitis prevalence and its associated factors in primary school children living in rural and urban areas in Kayseri Turkey. Cent Eur J Public Health.2013.21(2):104-8.

7. Manusamy $H$, Murhandarwati EE, Umniyati SR. The relationship between the prevalance of head lice infestation with hygiene and knowledge among the rural school children in Yogyakarta. TMJ. 2011. 01(02):102-9.

8. Natadisastra D, Ridad A. Parasitologi kedokteran. Jakarta: EGC; 2009.

9. Alatas SSS, Linuwih S. Hubungan tingkat pengetahuan mengenai pediculosis kapitis dengan karakteristik demografi santri pesantren X, Jakarta Timur. eJKI. 2013.1(1):53-7. 
10. AlBashtawy M, Hasna F. Pediculosis capitis among primary-school children in mafraq governorate jordan. Eastern Mediterranean Health Journal La Revue de Santé de la Méditerranéeorientale, 2010; 18(1):43-8.

11. Lesshaft $H$, Baier $A$, Guerra $H$, Terashima $A$, Feldmeier $H$. Prevalence and risk factors associated with pediculosis cappitis in an improverished urban community in Lima, Peru. Jurnal of Global Infectious Diseases Medknow Publication.2013;5(4):138-43.

12. Wolff K, Richard AJ. Color atlas and synopsis of clinical dermatology. USA: Mc Graw-Hill; 2009.

13. Fitria AN, Anwar C, Budi M. Prevalensi dan faktorfaktor yang memengaruhi perilaku sakit penderita pedikulosis kapitis di Panti Asuhan Kelurahan Sekip Jaya Kecamatan kemuning Palembang (skripsi). Palembang: Fakultas Kedokteran .Universitas Sriwijaya; 2015.

14. Fadilah $\mathrm{H}$. Perbedaan metode ceramah dan leaflett erhadap skor pengetahuan santriwati tentang pedikulosis kapitis di Pondok Pesantren Al-Mimbar Sambong Dukuh Jombang (skripsi).
Jakarta: Fakultas Kedokteran dan IImu Kesehatan Universitas Islam Negeri Syarif Hidayatullah; 2015.

15. Ansyah AN. Hubungan antara personal hygiene dengan angka kejadian pediculosis capitis pada santri putri Pondok Pesantren Modern Islam Assalaam Surakarta (skripsi). Surakarta: Fakultas Kedokteran Universitas Muhammadiyah; 2013.

16. Notoatmodjo, S. IImu perilaku kesehatan. Jakarta: PT Rineka Cipta; 2014.

17. Seif NY, Magda AA. Effect of breast selfexamination training program on knowledge, attitude and practice of a group of working women. Journal of the Egyptian Nat. Cancer Inst. 2000;(12)(2):105-15.

18. Zhen A, Herdiana E, Rahmah S. Head lice infestation and its relationship with hygiene and knowledge among urban school children in Yogyakarta. TMJ. 2011;01(01):35-41.

19. Bachok N, Nordin RB, Awang CW, Ibrahim NA, Naing L. Prevalence and associated factors of head lice infestation among primary school children in Kelantan, Malaysia. Southeast Asian J Trop Med Public Health. 2006;37(3):536-43. 